\title{
LONELINESS AND THE PARANOID SYNDROME
}

\author{
By
}

\author{
D. N. PARFitT, Hatton, Warwick
}

Paranoid reactions of various types are commonly found in women of late middle age or early senility.

Baugh ${ }^{1}$ described the prognosis of such cases as hopeless. He found that the patients had previously been indecisive, anxious, impressionable, touchy, scrupulous, introspective, self-satisfied and reticent before the first and final attack of insanity, and he believed that heredity was present in all. They were described as a special group of completely chronic cases by Smith, Macalister and Grimsdale, ${ }^{2}$ while Goodall and Craig ${ }^{3}$ had previously commented on their incidence and poor prognosis. More recently Jones and Minogue ${ }^{4}$ had 6 per cent. discharges in this group, which they described as consisting of paraphrenia, paranoia and severe delusional states, while Riddoch ${ }^{5}$ considered the prognosis very grave.

It is as yet impossible to divide these cases into completely separate groups. Riddoch describes them generally as marked by persistent ideas of reference, sexual discord and persecutory delusions with some mental deterioration. Maranon ${ }^{6}$ states that such psychoses vary and are not particular to the age, but that they appear in women with previous morbid nervous predisposition, even if only expressed as suspicious psychic peculiarities, and that heredity is often manifest. Jacobi ${ }^{7}$ believes that involution leads to increased observation of one's own body, to an inclination to anxiety, melancholy, suspicion and a general paranoic state of mind, that climacteric and involution are not the cause of disease, but only favourable soil for the development of disease. Farrar and Franks ${ }^{8}$ describe the group as including several varieties, such as cases with aggravation of constitutional personality trends, involutional paranoids, late cases of dementia præcox, and they remark on the difficulty of separating the involutional forms from those due to senescence, pointing out that other psychoses may be coloured by involutional and senile changes as well as the psychoses of this group. Fünfgeld 9 has described organic psychoses in two women of 60 and 61 respectively with symptoms strongly resembling those of late schizophrenic disease. Stevenson and Montgomery ${ }^{10}$ have attempted to describe as a clinical subentity a paranoid reaction occurring in women of middle age, with persecutory delusions but without intellectual deterioration, the psychosis becoming gradually apparent during the fifth and sixth decades and having 
as a specific ætiological factor an overt or imagined sinful act on the part of the patient who either projects the blame on others or denies that it would have been consciously desired by her. As a quietus to conscience a persecutory delusional trend is slowly developed. Kleist ${ }^{11}$ has described a presenile paranoic state as a separate process differentiated from paranoia by hallucinations, variations in mood, slow mentality and paucity of ideas terminating in a dementia which is not nearly so marked as in ordinary senile dementia ; and this conception has been supported by several other psychiatrists. Halberstadt 12 also describes a 'new' disorder commencing in women between 45 and 55 with depression, followed by melancholic delusions and finally delusions of persecution without anxiety, and demonstrates its lack of connexion with anxiety states, paraphrenia, schizophrenia, paranoia and other psychoses. Etiological factors which may be present are heredity, psychological difficulties, constitutional predisposition, anger and sorrow at the deprivations of age, menopausal changes, arteriosclerosis, autointoxication and cerebral involution.

Since all gradations from a functional psychosis occurring at or shortly after the menopause through the various types of insanity that have been briefly mentioned to a frank senile dementia could be described, it will be convenient for the present to consider these cases on an original Kraepelinian basis as examples of schizophrenia where the disease-process is not so acute as in dementia præcox and only becomes manifest after the stress of the climacteric or remains in abeyance until the deprivations and degenerations of presenility or senility are added to the menopausal changes. In this connexion Halberstadt ${ }^{12}$ quotes Kraepelin as describing presenile paranoid states presenting symptoms of dementia præcox though not seemingly connected with it, but Albrecht ${ }^{13}$ and Serko ${ }^{14}$ regarded the presenile paranoids as paraphrenics showing the schizophrenic taint.

This will suffice the more so as it is not the purpose of this note to discuss the classification of these disorders but to stress the frequency with which loneliness is a potent factor in the development of this group of psychoses. It must be stated that the very nature of the illness presupposes a tendency to introversion and withdrawal, but granting this, the state of social isolation having been once achieved, the solitude and the neglect are blamed on the environment and the stormy winds of suspicion and antagonism, gathering apace, drive the sufferer into the closed and windowless house of fully declared insanity.

\section{PERSONAL GASES}

The following brief case-histories of patients admitted to the Warwickshire and Coventry Mental Hospital within a period of six months illustrate the importance of loneliness and the variability of outcome.

Case I. M.A.B., female, age 61, widow.-By nature a kind and generous woman, but easily offended and stubborn in her resentment. She married at the age of 43 
and was a childless widow at 50. Thereafter she lived alone, her only friend being a married niece whom she visited at irregular intervals. Of recent years she had become increasingly suspicious and solitary, had ceased to visit her niece, who was discouraged by resentment and antagonism when she attempted to pay friendly calls upon her aunt.

When admitted to hospital she complained of persecution by men who tried to poison her and abused her through the walls of her house. She suffered from achlorhydric anæmia which responded to treatment.

Later she became reconciled to her niece, who was genuinely fond of her, and went out to live with her nine months after admission. She has remained well for four years.

Case II. C.H., female, age 46, single.-She was the youngest child of a family of four girls and two boys. She had drifted apart from her family and gradually ceased to correspond with any of them. For 15 years she was a companion help to an old lady, a suspicious and solitary woman of the type under consideration, who promised to make the patient independent. The death of the employer, however, left her with only her own small savings. She developed vague delusions of persecution by men who poisoned and robbed her. Certification revived the interest of her brothers and sisters. She was discharged to their care in four months and has remained well over four years.

Case III. E.B., female, age 73, single.-The elder by three years of two maiden ladies, both of whom had been much respected for their kindliness among neighbouring poor. Increasing poverty and the passing of years had lost them almost all their friends and they came to be regarded as two eccentric and peculiar outcasts in the country village in which they lived. Following a quarrel they separated, and the patient gradually developed a highly systematized delusion concerning two definite men, one of whom she thought had married her sister for her wealth, brutally ill-treated her and sold her possessions. In her anxiety to protect her sister from these ruffians she became so interfering and abusive that she had to be certified. Apart from her mental condition she had generalized arteriosclerosis and a high blood pressure.

After two and a half years in hospital she became reconciled to her sister and went out to live with her, still very deluded, but has kept fairly well for two years.

Case IV. A.M.C., female, age 68, widore.-The mother of seven children, she had been widowed early and worked heroically for them. As they grew up they left her, and for nine years she had lived alone, apart from an occasional lodger. She gradually developed a delusional system of persecution concerning a certain neighbour to whom she eventually showed active retaliation and was certified.

She had marked cardiovascular degeneration and high blood pressure.

She remains after five years in hospital a deluded and self-opinionated woman, but otherwise pleasant and only too eager to help in routine ward work. She has been nursed through two severe attacks of congestive heart failure and during the last two years her good nature has outbalanced her delusions and she has become responsive to the friendliness shown her.

Case V. L.B., female, age 47, single.-A nun since early youth, she had become gradually estranged from her sister nuns.

Hyperpiesis and persistent menorrhagia had made her duties and devotions rather irregular and she believed her colleagues were jealous of her enforced periods of leisure and that they spent their energies in devising petty annoyances for her.

She was admitted with delusions of persecution by men who 'put their spirits into her' but imagined herself under the protection of her cousin, a monk, who was always near her, disguised generally as a doctor.

After two years she was transferred to a convent hospital, more confirmed in her delusions than on admission.

Case VI. E.W., female, age 60, single.-An only child, she lived with her widowed 
mother for several years, on small private means. Seven years before admission her mother died and she had since been absolutely alone, regarded as an eccentric by her neighbours and avoided whenever possible. She developed delusions of persecution by male neighbours and imagined she was the wife of a general.

After admission she did a little occupational work, but this soon ceased and slowly increasing dementia is apparent after five years in hospital.

\section{DISCUSSION}

The adverse effects of loneliness are most typically seen in older patients of a presenile type. In general they are spinsters or widows whom the deaths of relatives or friends or the migration of children have left alone, feeling their loneliness, but too proud, self-willed and stubborn to seek to make it otherwise. Commonly they were women of strong personality in their healthy phase. The delusions often have a sexual significance and centre around persecution by men, often certain men known to the patients, whereby the double effect of the projection of blame and the acquisition of interest and attention is obtained.

Cardiovascular degeneration and high blood pressure are the commonest physical findings, but, like menopausal and senile changes, they merely enrich the soil for the growth of the persecutory system, although Seelert ${ }^{15}$ would explain all cases of this group, whatever the clinical feature, by the far-reaching effects of arteriosclerosis.

It is not suggested that loneliness is essential for the development of paranoid psychoses in middle age or early senility or that those cases where isolation is prominent form a separate clinical entity; but attention is drawn to the importance of considering this factor because in the early stages a satisfactory reaction to tactful friendliness is often obtained and the chief hope of holding off severe symptoms will sometimes lie in the possibility of uniting the patients to some friendly circle. The difficulty is that their lonely traits and the nature of their delusions generally leave them unrecognized and apart until the trouble is far advanced and certification is a necessity.

\section{REFERENCES}

1 Baugh, Brit. Med. Jour., 1910, $2,1244$.

2 Smith, Macalister and Grimsdale, Brit. Med. Jour., 1912, $2,1378$.

3 Goodall and Craig. Quoted by Smith et al.

4 Jones and Mrnogue, Med. Jour. Austr., 1927, $2,1378$.

5 Riddoci, Brit. Med. Jour., 1930, 2, 987.

- Maranon, The Climacteric (trans. by K. S. Stevens), London, 1929.

? JacoBi, Klin. Woch., 1930, 2, 1410.

8 Farrar and Franks, Amer. Jour. Psychiat., 1931, 10, 1031.

- Fúnfgeld, Monats. f. Psychiat. u. Neurol., 1933, 85, 210.

10 Stevenson and Montgomery, Amer. Jour. Psychiat., 1932, 11, 911.

11 Kleist, Allg. Zeits. f. Psychiat., 1913, 70, 1.

12 Halberstadt, L'Encéphale, 1932, 27, 273.

13 Albrecht, Zeits. f. d. g. Neurol. u. Psychiat., 1913, 22, 306.

14 Serko, Monats. f. Psychiat. u. Neurol., 1919, 45, 245.

15 Seelert, ibid., 1922, 52, 140. 